Umar, N.M., Noviekayati, I., \& Saragih, S. (2018). Efektivitas Personal Safety Skill Terhadap Peningkatan Kemampuan Mencegah Kekerasan Seksual pada Anak Ditinjau dari Jenis Kelamin. Indigenous: Jurnal Ilmiah Psikologi, 3(1), 45-50. doi:https://doi.org/10.23917/indigenous.v3i1.5815

\title{
Efektivitas Personal Safety Skill Terhadap Peningkatan Kemampuan Mencegah Kekerasan Seksual pada Anak Ditinjau dari Jenis Kelamin
}

\author{
Nurul Mahmudah Umar' ${ }^{1}$, IGAA Noviekayati², Sahat Saragih ${ }^{3}$ \\ Universitas 17 Agustus 1945 Surabaya ${ }^{123}$ \\ nurulmahmudahumar11@gmail.com¹ IGAA@gmail.com²Saragih@gmail.com³
}

\begin{abstract}
Abstraksi. Penelitian ini bertujuan menguji efektivitas Personal Safety Skill terhadap peningkatan kemampuan mencegah kekerasan seksual pada anak ditinjau dari jenis kelamin. Penelitian ini memiliki 3 variabel penelitian. Variabel Y kekerasan seksual adalah tindakan yang mengarah ke ajakan seksual seperti menyentuh, meraba, mencium, menonton produk pornografi, gurauangurauan seksual. Variabel X1 Personal Safety Skill adalah keterampilan keselamatan pribadi yang perlu dikuasai oleh anak agar dapat menjaga keselamatan dirinya dan terhindar dari tindakan kekerasan seksual yang memiliki tiga komponen yaitu Recognize, Resist, Report. Variabel X2 jenis kelamin adalah sifat jasmani atau rohani yang membedakan dua makhluk sebagai wanita dan pria. Pelatihan ini diikuti oleh 9 siswa dan 9 siswi TK PGRI Samboja. Teknik pengambilan sampel menggunakan Purposive sampling dengan menggunakan metode penelitian quasi eksperimen. Hipotesis pertama diuji dengan Teknik Kendall's W Test Wa score $=0.347$ dengan $\mathrm{p}=0.012$ $(\mathrm{p}<, 0,05)$ yang menunjukkan Personal Safety Skill efektif untuk meningkatkan kemampuan mencegah kekerasan seksual. Hipotesis kedua diuji Teknik Mann whitney $U$ test $Z=-1.737$ dengan nilai $\mathrm{p}=0.082$. Tidak ada perbedaan yang signifikan antara kekerasan seksual ditinjau dari jenis kelamin. Hipotesis ketiga diuji dengan Teknik Mann whitney $U$ test $Z=-2.160$ dengan nilai $\mathrm{p}=0.031 \mathrm{a}$ menunjukkan terdapat perbedaan yang signifikan terhadap Personal Safety Skill ditinjau dari jenis kelamin.
\end{abstract}

Kata kunci: Jenis Kelamin, Kekerasan Seksual, Personal Safety Skill

\section{PENDAHULUAN}

Kasus kekerasan seksual mengalami peningkatan setiap tahunnya. Korban kekerasan seksual bukan hanya orang dewasa dan remaja saja. Anak-anak hingga balitapun sering kali menjadi korban kekerasan seksual. Kekerasan seksual pada anak adalah pelanggaran moral dan hukum, serta melukai secara fisik dan psikologis.
Menurut Lyness (Maslihah, 2006) kekerasan seksual terhadap anak meliputi tindakan menyentuh atau mencium organ intim seksual anak, tindakan seksual atau pemerkosaan terhadap anak, memperlihatkan media/benda porno, menunjukkan alat kelamin pada anak dan sebagainya.

Berikut dapat di lihat pada tabel di bawah ini peningkatan dan penurunan jumlah kekerasan seksual dari tahun 2010 hingga 2017. 
Tabel 1. Jumlah Kekerasan dari tahun ke tahun

\begin{tabular}{cccc}
\hline No. & Tahun & Jumlah Kekerasan Pada Anak & Prosentase Kekerasan Seksual \\
\hline 1. & 2010 & 2.046 & $42 \%$ \\
2. & 2011 & 2.476 & $52 \%$ \\
3. & 2012 & 2.637 & $62 \%$ \\
4. & 2013 & 2.676 & $54 \%$ \\
5. & 2014 & 2.737 & $25 \%$ \\
6. & 2015 & 2.898 & $59,30 \%$ (201 Anak) \\
7. & 2016 & - & 120 Anak \\
8. & 2017 & - & 116 Anak \\
\hline
\end{tabular}

Fenomena meningkatnya kekerasan seksual terhadap anak, menunjukkan betapa dunia yang aman bagi anak semakin sempit dan sulit ditemukan. Hal ini dikarenakan kekerasan seksual pada anak bisa terjadi kapan saja dan di mana saja. Contoh kasus kekeraan seksual terhadap anak di Jakarta International School (JIS) yang tersingkap ketika salah satu orang tua murid dari JIS memberikan laporan kepada pihak kepolisian (Polda Metro Jaya) bahwa anaknya (pria) telah mengalami kekerasan seksual dengan cara disodomi oleh beberapa petugas kebersihan (Cleaning Service) di sekolah tersebut (Ismantoro, 2015).

Kasus kekerasan seksual bukan hanya terjadi di kota-kota besar tetapi hampir di seluruh wilayah Indonesia. Di Balikpapan Kalimantan Timur juga banyak terjadi kasus kekerasan seksual. Ibarat fenomena gunung es, banyak kasus yang tidak muncul kepermukaan dan berakhir dengan perdamaian (kompas.com, diakses 24 april 2017). Tenggarong Kalimantan Timur seorang guru SD menjadi tersangka kasus sodomi terhadap seorang siswanya (http//m. merdeka.com, diakses 23 april 2014).

Kekerasan seksual pada anak bukan hanya terjadi pada anak perempuan tetapi juga terjadi pada anak laki-laki. Data Kementerian Pemberdayaan Perempuan dan Perlindungan Anak (Kementerian PPPA) bersama Badan Pusat Statistik dan Kementerian Sosial pada tahun 2013, 8,5 persen anak laki-laki dari 87 juta anak Indonesia menjadi korban kejahatan seksual. Angka kejahatan tersebut dua kali lipat lebih besar dibandingkan yang terjad pada anak perempuan yang sebesar 4,2 persen. Kekerasan seksual terhadap anak laki-laki jumlahnya lebih dari 900 ribu. Meskiun kasus tersebut mendominasi, kekerasan seksual pada anak lakilaki jarang ada yang terungkap atau melaporkan kepada aparat penegak hukum. Anak laki-laki tidak pernah melapor membuat seakan-akan yang selalu terkena kekerasan seksual adalah anak perempuan. Tidak dilaporkannya kasus kekerasan seksual pada anak laki-laki disebabkan anggapan masyarakat menegnai karakter laki-laki yang maskulin. Budaya tersebut membiasakan anak laki-laki tidak boleh menangis, cengeng. Hal tersebut mendorong anak menjadi tertutup untuk melaporkan masalah seksual kepada orang tua maupun aparat penegak hukum (http// nasionalkompas.com, 2016).

Anak perempuan maupun anak laki-laki tentu tidak boleh dibiarkan begitu saja. Hal tersebut dikarenakan kekerasan seksual terhadap anak dapat terjadi kapan saja dan di mana saja. Siapa pun bisa menjadi pelaku kekerasan seksual terhadap anak, karena tidak adanya karakteristik khusus. Setiap orang dapat dicurigai berpotensi melakukan kekerasan seksual, namun umumnya pelaku adalah orang yang dikenal oleh korban. Pelaku dapat berasal dari berbagai tingkat social. Beberapa pelaku merupakan orang yang memiliki pengaruh didalam komunitas dan memiliki posisi kerja yang dekat dengan anak, terutama dalam kasus pedofilia. Pelaku dalam kasus pornografi dan prostitusi dapat melibatkan orang asing, maupun orang tua dari anak (wong at al., 2008).

Berdasarkan fakta-fakta mengenai kasus kekerasan seksual pada anak dan jumlah korban yang setiap tahun terus menerus meningkat, sehingga anak perlu diberikan pelatihan untuk mencegah kekerasan seksual yang dapat terjadi kapanpun dan di manapun anak berada. Salah satu upaya pencegahan dapat dilakukan melalui pengajaran Personal Safety Skills atau keterampilan 
keselamatan pribadi pada anak.

Personal Safety Skills adalah pendidikan yang diajarkan kepada anak tentang apa yang harus dilakukan jika terjadi situasi yang dapat membahayakan mereka untuk menjaga diri mereka tetap aman. Pendidikan ini tidak hanya mengurangi resiko menjadi korban tetapi juga meningkatkan kemampuan anak untuk melindungi diri mereka sendiri (Kendall, 2012).

Personal Safety Skill atau keterampilan keselamatan pribadi merupakan seperangkat keterampilan yang perlu dikuasai oleh anak agar dapat menjaga keselamatan dirinya dan terhindar dari tindakan kekerasan seksual (Bagley dan King, 2004). Personal Safety Skills terdiri atas tiga komponen keterampilan. Pertama adalah recognize, yakni kemampuan anak mengenali ciri-ciri orang yang berpotensi melakukan kekerasan seksual (predator). Kedua Resist, yakni kemampuan anak bertahan dari perlakuan atau tindakan kekerasan seksual. Ketiga Report, yakni kemampuan anak melaporkan perilaku kurang menyenangkan secara seksual yang diterimanya dari orang dewasa, bersikap terbuka kepada orang tua agar orang tua nya dapat memantau kondisi anak tersebut.

\section{METODE PENELITIAN}

Pengambilan sample penelitian adalah dengan menggunakan teknik Purposive sampling yaitu pemilihan sekelompok subjek penelitian berdasarkan ciri-ciri tertentu dari subjek penelitian yang dipakai dalam penelitian kali ini. subjek dalam penelitian ini adalah siswa prasekolah usia 5-6 tahun, siswa tersebut belum pernah mendapatkan pelatihan Personal Safety Skill. Sehubungan dengan hal tersebut, maka variabel-variabel dalam penelitian ini sebagai berikut :

1. Variabel Y/ Variabel Tergantung: Kekerasan seksual

2. Variabel X1/ Variabel Bebas: Personal Safety Skill

3. Variabel X2/ Variabel Bebas: Jenis Kelamin

Dalam penelitian ini subjek penelitian berjumlah 18 siswa.

Pada penelitian ini dengan skala Personal Safety Skill uji realibilitas alat ukur dalam penelitian ini menggunakan SPSS 17 dan hasil yang didapatkan Cronbach's Alpha $(\mathbb{\nabla})=0,784$ dimana a $>0.7$ dikatakan cukup tinggi, artinya instrumen pengukuran yang dipakai dalam penelitian ini reliabel.

Analisis data ada tahap intervensi dilakukan menggunakan teknik analisa data statistik non parametrik Kendal W test dan Mann Whitney $U$ test dengan Statistical produck and Service Solution (SPSS) 17 for windows, dilakukan untuk membandingkan selisih antara skor Pretest dan skor Posttest untuk mengetahui efektivitas Personal Safety Skill terhadap kemampuan mencegah kekerasan seksual dan untuk mengetahui skor kelompok anak laki-laki dan anak perempuan terhadap Personal Safety Skill dan kekerasan seksual.

Pelatihan ini juga melatih anak untuk mampu bertahan dari perlakuan atau tindakan kekerasan seksual, misalnya berteriak minta tolong, memberitahu orang lain bahwa orang yang menggandengnya bukanlah ayah atau ibunya, dan sebagainya. Kemampuan ini anak diajarkan kepada anak untuk mengidentifikasi sejumlah tindakan yang dapat ia lakukan ketika berhadapan dengan pelaku kekerasan seksual atau ketika berada dalam situasi yang memungkinkan terjadinya tindakan kekerasan seksual. Anak diajari untuk dapat mengabaikan rayuan dan bujukan dari orang yang berpotensi melakukan kekerasan seksual, mengatakan “Tidak!" atau "Stop!" dengan lantang dan tegas pada orang yang mencoba melakukan tindak kekerasan seksual pada mereka, melakukan tindakan perlawanan seperti memukul, menggigit, menendang pada pelaku kekerasan seksual, melarikan diri dari pelaku kekerasan seksual dan berteriak.

\section{HASIL DAN PEMBAHASAN}

Penelitian ini tidak ada kelompok kontrol, namun penelitian ini terdapat pengujian mengenai perbedaan efektivitas pelatihan Personal Safety Skill ditinjau dari jenis kelamin.

Sebelum dilakukan penelitian, peneliti melakukan penggalian data terlebih dahulu dengan cara observasi dan wawancara dengan pihak terkait dan memberikan Personal Safety Skill dan penggunaan skala kekerasan seksual pada subjek penelitian di TK PGRI Samboja. Data 
yang diperoleh diantaranya, nama subjek, usia, yang kedua. Pada hipotesis ini menggunakan jenis kelamin dan kelas serta hasil pengukuran skala Personal Safety Skill diperoleh nilai pretest dan post-test sebelum dan setelah diberikan perlakuan.

Dari data yang telah didapatkan kemudian dianalisis untuk melakukan pengujian hipotesa statistik nonparametrik SPSS Statistics Version 17 dengan Teknik Mann Whitney $U$ test digunakan untuk mengetahui perbedaan median dua kelompok bebas apabila skala data variabel terkaitnya adalah ordinal tetapi tidak berdistribusi normal.

Tabel 2. Personal Safety Skill Ditinjau Dari Jenis Kelamin

\begin{tabular}{llrrr}
\hline & & & & \\
\hline & Jenis_Kelamin & N & Mean Rank & Sum of Ranks \\
\hline \multirow{2}{*}{ PreTest_LakiLaki } & Laki-laki & 9 & 13.17 & 118.50 \\
Perempuan & Perempuan & 9 & 5.83 & 52.50 \\
& Total & 18 & & \\
PostTest_ & Laki-laki & 9 & 12.17 & 109.50 \\
LakiLakiPerempuan & Perempuan & 9 & 6.83 & 61.50 \\
& Total & 18 & & \\
\hline
\end{tabular}

Tabel 3. Hasil Kategori Pretest-postest Personal Safety Skill Masing-masing Subyek

\begin{tabular}{|c|c|c|c|c|c|c|}
\hline \multirow{2}{*}{ No. } & \multirow{2}{*}{ Nama } & \multicolumn{2}{|c|}{ Pretest } & \multicolumn{2}{|c|}{ Posttest } & \multirow{2}{*}{ Keterangan } \\
\hline & & Skor & Kategori & Skor & Kategori & \\
\hline 1. & MA & 6 & RS & 15 & $S$ & Meningkat \\
\hline 2. & HR & 14 & $\mathrm{R}$ & 13 & $\mathrm{R}$ & Menurun \\
\hline 3. & DA & 11 & $\mathrm{R}$ & 13 & $\mathrm{R}$ & Meningkat \\
\hline 4. & MD & 16 & S & 16 & $S$ & Tetap \\
\hline 5. & ML & 8 & $\mathrm{RS}$ & 14 & $\mathrm{R}$ & Meningkat \\
\hline 6. & MR & 16 & S & 16 & $S$ & Tetap \\
\hline 7. & $\mathrm{AH}$ & 14 & $\mathrm{R}$ & 14 & $\mathrm{R}$ & Tetap \\
\hline 8. & $\mathrm{AE}$ & 15 & S & 15 & S & Tetap \\
\hline 9. & AR & 15 & S & 15 & $S$ & Tetap \\
\hline 10. & $\mathrm{AL}$ & 2 & RS & 8 & RS & Meningkat \\
\hline 11. & $\mathrm{AA}$ & 6 & RS & 13 & $\mathrm{R}$ & Meningkat \\
\hline 12. & AI & 1 & RS & 10 & $\mathrm{R}$ & Meningkat \\
\hline 13. & $\mathrm{AC}$ & 3 & RS & 11 & $\mathrm{R}$ & Meningkat \\
\hline 14. & NB & 7 & RS & 15 & $S$ & Meningkat \\
\hline 15. & NF & 7 & RS & 13 & $\mathrm{R}$ & Meningkat \\
\hline 16. & SY & 12 & $\mathrm{R}$ & 16 & $S$ & Meningkat \\
\hline 17. & FT & 7 & RS & 13 & $\mathrm{R}$ & Meningkat \\
\hline 18. & MR & 7 & RS & 11 & $\mathrm{R}$ & Meningkat \\
\hline
\end{tabular}

Dari hasil analisis data pada tabel 1 diatas kelompok eksperimen memperoleh skor $\mathrm{Z}$ $=-2.160$ dengan nilai $\mathrm{p}=0.031$ Karena nilai $\mathrm{p}<0.05$, maka hipotesis ketiga signifikan atau diterima. Maka secara statistik terdapat perbedaan yang signifikan Personal Safety Skill ditinjau dari jenis kelamin. Untuk perbedaan secara mean diperoleh hasil anak laki-laki sebesar dari 13.17 menjadi 12.17 sedangkan anak perempuan dari 5.38 menjadi 61.50 .

Data analisa kualitatif didapat dari hasil wawancara sebelum dan sesudah diberikan pelatihan Personal Safety Skill yang dilakukan di TK PGRI Samboja. Guru TK PGRI 
mengatakan sebelumnya bahwa anak belum pernah mendapatkan pelatihan Personal Safety Skill di sekolah. Kemudian setelah dilakukan pelatihan Personal Safety Skill terdapat adanya perubahan yaitu anak mengetahui bagianbagian dari tubuhnya yang boleh dilihat atau disentuh oleh orang lain, jenis-jenis sentuhan serta apa yang harus dilakukan apabila kejadian tersebut mereka alami.

Sesuai dengan hasil dari pengisian skala bahwa terlihat ada beberapa anak yang belum mengetahui beberpa bagian dari tubuhnya yang boleh dan tidak boleh disentuh. Hasil dari pretest dan post tes anak terhadap pelatihan Personal Safety Skill.

Pada uji hipotesis Personal Safety Skill efektif untuk meningkatkan kemampuan mencegah kekerasal seksual pada anak dengan menggunakan analisis Kendall's diperoleh Wa score $=0.347$ dengan $\mathrm{p}=0.012(\mathrm{p}<, 0,05)$. Artinya Personal Safety Skill efektif untuk meningkatkan kemampuan mencegah kekerasan seksual pada anak, sebelum diberikan pelatihan dan setelah diberikan pelatihan.. Hal ini menunjukkan bahwa anak mampu menyerap informasi yang diberikan pada saat pelatihan.

Pada uji hipotesis selanjutnya ada perbedaan kekerasan seksual ditinjau dari jenis kelamin dengan analisis menggunakan Mann Whitney $U$ test diperoleh data kelompok eksperimen memperoleh skor $\mathrm{Z}=-1.737$ dengan nilai $\mathrm{p}$ $=0.082$. Karena nilai $\mathrm{p}>0.05$, maka hipotesis ditolak. Yang artinya tidak ada perbedan secara signifikan kekerasan seksual yang terjadi antara anak perempuan dan anak laki-laki . Meskipun tidak ada perbedaan kekerasan seksual pada anak laki-laki dan anak perempuan secara signifikan namun secara rata-rata yang diperoleh anak perempuan memperoleh angka 11.67 dan anak laki-laki 7.33. hal tersebut menunjukkan bahwa anak perempuan lebih rentan menjadi korban kekerasan seksual di banding anak laki-laki.

Data analisa kualitatif didapat dari hasil wawancara sebelum dan sesudah diberikan pelatihan Personal Safety Skill yang dilakukan di TK PGRI Samboja. Guru TK PGRI mengatakan sebelumnya bahwa anak belum pernah mendapatkan pelatihan Personal Safety Skill di sekolah. Kemudian setelah dilakukan pelatihan Personal Safety Skill terdapat adanya perubahan yaitu anak mengetahui bagianbagian dari tubuhnya yang boleh dilihat atau disentuh oleh orang lain, jenis-jenis sentuhan serta apa yang harus dilakukan apabila kejadian tersebut mereka alami.

Sesuai dengan hasil dari pengisian skala bahwa terlihat ada beberapa anak yang belum mengetahui beberpa bagian dari tubuhnya yang boleh dan tidak boleh disentuh. Hasil dari pretest dan post tes anak terhadap pelatihan Personal Safety Skill terlihat rata-rata anak yang mengalami peningkatan pengetahuan mencegah kekerasan seksual.

Pada uji hipotesis selanjutnya ada perbedaan Personal Safety Skill ditinjau dari jenis kelamin dengan analisis menggunakan Mann Whitney $\mathrm{U}$ test diperoleh skor $\mathrm{Z}=-2.160$ dengan nilai $\mathrm{p}=0.031$ Karena nilai $\mathrm{p}<0.05$, maka hipotesis ketiga signifikan atau diterima. Maka secara statistik terdapat perbedaan yang signifikan Personal Safety Skill ditinjau dari jenis kelamin. Untuk perbedaan secara mean diperoleh hasil anak laki-laki dari 13.17 menjadi 12.17 sedangkan anak perempuan dari 5.38 menjadi 61.50 .

Hasil penelitian yang menunjukkan bahwa tidak ada perbedaan Personal Safety Skill pada anak laki-laki maupun perempuan terhadap kemampuan mencegah kekerasan seksual pada anak terjadi karena pada masa ini anak laki-laki maupun anak perempuan berada pada masa perkembangan kognitif yang sama sehingga dalam penyerapan informasi yang telah diberikan sama.

\section{SIMPULAN}

Kasus kekerasan seksual pada anak yang semakin banyak terjadi di Indonesia, salah satu faktor penyebab terjadinya kekerasan seksual pada anak tersebut disebabkan kurangnya pengetahuan anak tentang bagian tubuh pribadi yang dimiliki anak yang tidak boleh disentu oleh orang lain. Kurangnya kemampuan anak mendeteksi pelaku kekerasan seksual serta kurangnya keterampilan melindungi diri dari bahaya kekerasan seksual yang bisa terjadi dimana saja dan kapan saja. Personal Safety Skill sangat dibutuhkan oleh anak guna melindungi dirinya dari pelaku kekerasan seksual. Hal ini 
dikarenakan Personal Safety Skill melatih anak untuk mengetahui bagian tubuh pribadinya, pelaku kekerasan seksual serta apa yang harus dilakukan saat menghadapi kekerasan seksual.

Hasil penelitian ini menunjukkan bahwa Personal Safety Skill efektif dalam meningkatkan kemampuan dalam menecegah kekerasan seksual pada anak. Pemilihan subjek anak-anak dalam penelitian ini dikarenakan banyaknya anak yang menjadi korban kekerasan seksual, karena anak belum memiliki keterampilan perlindungan diri. Anak belum mengetahui area tubuh pribadinya, anak mudah dirayu, serta anak tidak mengetahui bahaya dan tidak mampu mengidentifikasi pelaku kekerasan seksual yang bisa saja adalah orang terdekat dari anak.

Hasil lainnya dari penelitian ini adalah tidak ada perbedaan antara anak laki-laki dan perempuan terhadap kemungkinan terjadinya kekerasan seksual meskipun dari segi rata-rata terlihat lebih rentan anak perempuan yang mengalami kekerasan seksual dibanding anak laki-laki, namun hal ini tidak menjamin bahwa anak laki-laki juga rentan terkena kekerasan seksual dan bukan hanya terjadi pada anak perempuan saja.

\section{DAFTAR PUSTAKA}

Azwar, S. (2001). Metode Penelitian. Yogayakarta: Pustaka Pelajar

Bagley, C., \& Kathleen, K. (2004). Child sexual abuse: the search for healing. New York : Routledge. Bayu, D. J. (2016, Oktober 02). Meski Sering Alami Kejahatan Seksual, Anak Laki-laki Tak Banyak Melapor. Diambil tanggal 12 Januari 2018, dari http://nasional.kompas.com/ $\mathrm{read} / 2016 / 10 / 02 / 13384091 / \mathrm{meski}$.sering.alami.kejahatan.seksual.anak.laki-laki.tak.banyak. melapor

Finkelhor. (2009). The international epidemiology of child sexual abuse: a continuation of Finkelhor (1994). Child Abuse Negl, Jun; 33(6):331-42. doi: 10.1016/j.chiabu.2008.07.007.

Harahap, L. H. (2014) Studi Tentang Proses Penyelidikan Kasus Pedofilia di Yogyakarta, Yogyakarta : UIN Kalijaga, h.77.

Kendall, P.C. (2012). Child and Adolescent Therapy : Cognitive-Behavioral Procedures. New York : The Guildford Press.

Ramadhian, F. (2014, April 23). Guru SD di Kutai jadi tersangka Pedofilia. Diambil tanggal 01 Januari 2018, dari https:/www.merdeka.com/peristiwa/guru-sd-di-kutai-jadi-tersangkapedofilia.html

Tabachnick, J., \& Pollard, P. (2016). Considering Family Reconnection and Reunification after Child Sexual Abuse. A Road Map for Advocates and Service Providers. Enola : National Sexual Violence Resource Center.

Wong, D. L., Hockenberry, E. M., Wilson, D., Winkelstein, M. L., \& Schwartz, P. (2008). Buku Ajar Keperawatan Pediatrik Wong Vol. 1 6th ed. Jakarta: EGC. 